mathematics, physics, medicine and biology. Socrates developed the method of argument, and Aristotle was the founder of formal logic. Rome followed during 100 B.C.-A.I, 400 with contributions to engineering, government and the formulation of law. And so one could go on. This is the history of discovery-not the discovery of natural laws alone, but also of human relations.

It is certain that our science students need a much broader and deeper background to their training. They need to be given training not only in scientific method but also in the interrelation of science with the other cultural disciplines. By giving them this we make them think of themselves not only as wheels in a machine concerned only with their own move. ments, but also as necessary parts of that machine, the working of which they seek to understand-the machine of human culture.

All this, the British Association Committee clearly bears in mind in its deliberations, and for this it is to be congratulated on a very valuable piece of work, which, nevertheless, is only partially completed. The Committee has, much to its credit, kept in mind the most important needs in our universities of the future, namely, equality of opportunity, freedom of development, thought and speech, the promotion of international collaboration, needs and service of the community-or in one phrase, training for world citizenship.

\section{BRITISH ASSOCIATION REPORT}

$\mathrm{O}$ $\mathrm{NE}$ of the important questions raised at the Conference on Science and World Order, which was held in London during September 1941, under the auspices of the British Association Division for the Social and International Relations of Science', was that of post-war university education and the rehabilitation of universities destroyed or damaged during the War. A Committee was consequently formed to examine and report on the problems involved. This Committee, under the chairmanship of Dr. J. C. Maxwell Garnett, is composed of twentyfour members (several representing universities outside the British Empire), together with the president and general officers of the British Association, and Prof. F. E. Weiss and Mr. A. Gray Jones as joint honorary secretaries. The Committee presented an interim report to the Council of the British Association in September 1942, and this has now been published $^{2}$.

\section{Entrance to Universities}

The Committee recognizes that those who enter upon a university career should do so with a greater maturity of mind and a wider experience of life than has hitherto been the case. 'The 'modal' age of entry into the universities should therefore be not less than nineteen. During their nineteenth year, students should carry out some approved form of national or international service (civil or military). Where possible, this work should be related to the intended profession of the students of applied science. For example, engineers should do a year of workshop training, and medical students might either enter a hospital or do some other form of welfare work. In other cases, a year abroad could be accepted as one form of international service.

Entrance examinations should consist of two parts :
(1) a test of general education ; (2) a test of special knowledge. So far as (1) is concerned, an everwidening group of universities (beginning with all those in the United Kingdom) should adopt each other's tests. This would not apply to (2), but each department of each university should satisfy itself concerning a candidate's special knowledge. Though this recommendation would not be seriously impaired if certain universities still insisted upon every candidate for matriculation possessing, as part of a general education, some one particular kind of knowledge (for example, Greek or Latin) not required by other universities in the group, the Committee expresses the view that the adoption of its recommendations should be subject to no such exception.

Personal character (purposefulness, enterprise, initiative and originality) should receive careful consideration, together with the generally examined knowledge and intellectual qualities of a candidate when he is being considered for a university entrance scholarship. One of the greatest advantages of this, so far as each individual is concerned, would be to increase equality of opportunity. The schools themselves would also benefit in that they would thus be encouraged to provide more all-round training, especially social, by means of out-of-school activities.

For every internal student, at least one year's residence in college or hostel should be enforced. The Committee states that this would not involve a prohibitive cost; but further inquiries are being made. Personal direction and watching of every undergraduate's studies should be more fully deve. loped by the adoption or extension of the tutorial system.

Freedom for discussion should be the keynote of all university education. Freedom of thought and expression, especially so far as world affairs are concerned, should be assured.

\section{An International Auxiliary Language}

International communication will be indispensable after the War, and the universities can contribute towards this by requiring all their students to be able to make themselves understood, by speech and writing, in some one auxiliary means of international communication. This is not a question of learning another language but of devoting one long vacation to the acquisition of an auxiliary means of communication. Basic English, for example, has only 850 words, whereas the English language contains 240,000, while French has 100,000 and Italian 80,000 words. A sufficient acquaintance with Basic English could be obtained within a few days by the many post-war students who will be able to talk some English. Professional diplomats can, of course, transact their business in a common language. Since it ceased to be Latin it has generally been French and is likely, in future, to be English. English is one of the two languages of the Anglo-Soviet Treaty and the common language of Generalissimo Chiang Kai-shek and the peoples of India.

The desirability of promoting the introduction of an auxiliary language as an international means of communication was given particular attention after the War of 1914-18, and the position and prospects of this subject were surveyed in a report of a British Association Committee published in 1921. In order to present the problem in a comprehensive manner, the Committee communicated with leading authorities and associations having special knowledge of classical 
and modern languages as well as interest in the use of an international auxiliary language. The particular claims of three types of such a language were stated, namely: (1) A dead language, for example, Latin; (2) a national language, for example, English; (3) an invented or artificial language, for example, Esperanto and Ido.

The advantages and disadvantages of each of these types were considered by the Committee, which reached the following conclusions: (1) Latin is too difficult to serve as an international auxiliary language; (2) the adoption of any modern national language would confer undue advantages and excite jealousy ; (3) therefore an invented language is best. Esperanto and Ido are suitable, but the 1921 Committee was not prepared to decide between them.

However, since the publication of the British Association's report twenty-one years ago, the great political changes which have taken place, or which will have taken place at the end of the War, point to the fact that any auxiliary means of communication will have to be closely related to the English language. The Universities Bureau of the British Empire, and the new Association of University Professors and Lecturers of Allied Countries in Great Britain $^{3}$, might well assist in promoting the movement for an auxiliary means of international communication by preparing a report on the question whether Basic English is suitable for the purpose, or, if not, what alternative is to be preferred.

\section{International Education Organization}

Experience in university and other kinds of education gained by the different countries of the world should be pooled by the formation of an international education organization representative of teachers (including university teachers), governing bodies, local education authorities and governments. The wider utilization of graduate scholarships, sufficient to cover passage money and all necessary expenses, should aid the exchange of students between the universities of different countries.

The universities should also associate themselves more closely with non-vocational adult education.

\section{Replanning University Curricula}

Another term of reference of the British Association Committee is "To consider the replanning of teaching departments and curricula in accordance with modern conceptions of the interrelations of different branches of knowledge, particularly those of science and the humanities".

University studies are still showing a tendency to split up into a growing number of separate specialisms, very remarkable for their diversity. These tend to become increasingly removed from the life of the community. The Committee has therefore considered two proposals : $A$, a general degree course including both natural sciences and the humanities; $B$, a proposal to include courses of the elements of sociology and citizenship in the already existing specialized schools of natural and applied sciences.

The recommendations concerning $A$ are partly derived from the proposals for an Honour School of Philosophy and Natural Science which were considered in 1923 by the University of Oxford and which have recently been informally revived. The crux of the recommendation is the institution of honours and pass schools of "Philosophy, Natural and Social". Here the modern world would be studied as an integrated whole against a background of modern science. The course of study would include the natural and the social sciences with the ultimate aim of constructing (as expressed in Whitehead's "Process and Reality") "a system of ideas which bring the resthetic, moral and religious interests into relation with those concepts of the world which have their origin in natural science".

In such a course, chemistry and physics would come together under 'physical science', and zoology, botany and physiology under 'biological sciences'. During the study of these subjects, detailed knowledge would be looked upon as being less important than an apprehension of scientific method. Observational and experimental work would, however, have to be included. Along with these courses, there should be courses in the history of discovery, not only of inventions but also of ideas and conceptions. The study of man and society, including the contemporary international community, should be begun in the first year and extend through the next. The last year would then link together all previous work, whether in natural sciences or the humanities, and bring it in relation with the best philosophic thought of the Western world, begun by Plato and Aristotle and continued by the greatest modern thinkers from Descartes to Whitehead.

The Committee gives a warning against having separate tutors directing study of the separate subjects ; the whole course must, to be effective, be treated as an integrated whole-an organized unity.

Proposal $A$ is designed by the Committee to provide for the "non-vocational education of citizens". Proposal $B$ should ensure that the importance of the interrelation of science and the humanities be also recognized in the specialized courses for students preparing for a professional vocation of science. For reasons stated by the Committee (and reiterated time and time again in NATURE and elsewhere), all students in the faculties of science should attend some discussion classes in subjects outside their specialism. Here such students should be addressed by persons who understand their background interest; the students are not recommended to attend courses of lectures in the faculties of arts and commerce.

There should be "special interest" courses; for example, medical students should attend courses on the public health services, vital statistics and human needs. These "special interest" courses should be followed by courses made up of discussion groups of a more general nature on citizenship, social and industrial relations, anthropology, psychology, and other branches of the humanities.

Such courses should cover the student's first two years, and should be enough to enable him to start thinking about social affairs, so that later on in his university career he will take complete advantage of the debating and political societies organized by the students themselves in their unions and guilds.

While claiming that all this is going in the right direction, the Committee warns against forcing the pace. The new teachers with the new outlook must eventually be created. This can be done, $(a)$ by teaching general science in all schools, and $(b)$ by providing courses in borderline subjects in the universities, such subjects to include social medicine and vital statisties in the faculties of science and medicine, social technology, demography and standards of human needs in the faculties of arts and commerce. 


\section{Rehabilitation of War-Damaged Universities}

The British Association Committee has under survey the position regarding teaching material, apparatus, books and strff in universities which have been destroyed, damaged, disorganized or closed as a result of the War.

The Committee recommends that the United Nations should, at the time of armistice, require the enemy Powers to make full restoration of university property stolen or destroyed in the countries they have temporarily occupied.

Many scientific instruments and much apparatus now being put to war purposes would be of great value for teaching and research, and the Committee recommends that the Governments of the United Nations either give or lend them to the universities, especially those being rehabilitated after the War, and that they require similar action of the enemy Powers.

The Committee has obtained much information from the London International Assembly concerning war damage to the universities. Lists of up-to-date text-books as well as standard books and works of reference are being compiled. When these are sufficiently complete, they will be sent to British universities and university colleges and to the American University Union. It is then hoped to collect a large number of spare copies of such works. The Committee also recommends that the British Council consider buying certain books, and it is also hoped that publishers may supply, for the use of rehabilitated universities, books at reduced prices. It is also hoped to collect copies of learned journals or microfilms of them. The Committee may be able to arrange for the preparation of such microfilms.

It is the opinion of some members of the Committee, who are citizens of the Allied States in Europe, that it will be necessary for British and American universtities to train teachers and research workers for some of the universities whose staffs have been killed or dispersed by the enemy.

1 NATURE, 148, 331, 388, 393, 424, 426, 454, 456 (1941).

a "The Advancement of Science", 2 , No. 7, 255 (1942). British 'The Advancement of Sclence, London, w.1. 5 s.

${ }^{3}$ NATURE, 150, 692 (1942).

\section{RECENT ADVANCES IN OUR KNOWLEDGE OF THE PHOTO- GRAPHIC PROCESS*}

\section{By $D_{R}$. C. E. KENNETH MEES, F.R.S. \\ Research Laboratory, Eastman Kodak Company}

W

HILE many materials are sensitive to light and can be used for making photographs, the present art of photography is based upon one specific process : the light-sensitive material is silver bromide in the form of extremely small crystals held in a layer of gelatin.

The direction in which advances have beon made in recent years is in the elucidation of the structure of the light-sensitive materials and the factors which produce great sensitivity in the silver bromide crystals, so that very small amounts of light are sufficient to make them developable ; in the study of

- Abridged from Scientific Monthly (Lancaster, Pa.), 55, No. 4, 293-300 (Oct. 4,1942 ). the action of light itself and of the change which occurs in the exposed crystals; and in the study of the development reaction by which the exposed crystals are reduced to metallic silver.

The nature of the silver halide crystals and the origin of their sensitivity were elucidated between 1920 and 1930. An adequate theory of the nature of the reaction of light has only become available in the last three or four years, and our views as to the nature of the development reaction have changed very radically in the last year or two.

About twonty years ago, an attack was made on the origin of the sensitivity of the silver bromide crystals by three groups of investigators-Svedberg and his collaborators in Sweden, the British Photographic Research Association in England and the Kodak laboratories in Rochester, N.Y. Soon after gelatin emulsions were first made, it was found that the exposure required in the camera was greatly lessened if the emulsion had been cooked for some time at a high temperature or if it had been treated with ammonia. It was observed that the grains had grown larger during this treatment, and it was concluded that their greater sensitivity was due to their greater size. This is true, but it is by no means the whole story. For a long time, it had been known that if an emulsion were treated with some chemicals, such as chromic acid, it lost its sensitivity, even though the size of the grains was not changed. Also, sensitivity depends very much upon the particular kind of gelatin used in making the emulsion. No clue to an explanation was found until Dr. S. E. Sheppard studied systematically the various fractions obtained at each stage in the preparation of photographic gelatin.

Photographic gelatin is made from clippings from the skins of calves. For this purpose, the skin of the face and ears is used because these parts are of no value for leather. These clippings are first washed and then treated with lime for a long time to remove the fat and hair. The lime is removed by long washing with weak acid and then with water. Then the material is cooked in steam kettles until the gelatin is extracted, and the extract is concentrated if necessary and allowed to set to a jelly; the blocks of jelly are cut into thin slices and stretched out on nets to dry. Sheppard found that in the acid liquors in which the limed clippings had been washed there seemed to be a concentration of some sort of sensitizer, eventually identified as mustard oil, which contains sulphur.

When mustard oil is treated with alkali, it forms allyl thioearbamide. If silver bromide is treated with a solution of allyl thiocarbamide, the surface of the silver bromide is attacked and grows a mass of white needles containing both allyl thiocarbamide and silver bromide. When these are treated with alkali, they break down into little black spots which must consist of silver sulphide because of the chemistry of the reaction.

When the development of grains is observed under the microscope, it starts from specks, these increasing in number and size until each grain is transformed into metallic silver. The question arises as to whether these centres of development existed before exposure or came into existence when development started. Sheppard's work put the whole matter beyond doubt. Sensitivity depends upon the existence of specks far too small to be seen in the microscope, and these specks consist of silver sulphide, probably derived from the mustard oil in the gelatin. The amount of 